\title{
INSULT TO INJURY: DISABILITY, EARNINGS, AND DIVORCE
}

\author{
Perry Singleton* \\ CRR WP 2009-25 \\ Released: November 2009 \\ Draft Submitted: November 2009 \\ Center for Retirement Research at Boston College \\ Hovey House \\ 140 Commonwealth Avenue \\ Chestnut Hill, MA 02467 \\ Tel: 617-552-1762 Fax: 617-552-0191
}

* Perry Singleton is an assistant professor of economics at Syracuse University and a senior research associate at the Center for Policy Research. The research reported herein was pursuant to a grant from the U.S. Social Security Administration (SSA) funded as part of the Retirement Research Consortium (RRC). The opinions and conclusions expressed are solely those of the author and do not represent the views of SSA, any agency of the federal government, Syracuse University, the RRC, or Boston College. The author would like to thank Kimberly Burham, Mark Duggan, Jeffrey Kubik, Joyce Manchester, David Pattison, Christopher Rohlfs, Seth Sanders, and Mircea Trandafir for helpful comments and suggestions. The study is supported financially by a Steven $\mathrm{H}$. Sandell Grant, administered by the Center for Retirement Research at Boston College and funded by SSA. All comments and errors are the authors and do not reflect the views of SSA.

(C) 2009, by Perry Singleton. All rights reserved. Short sections of text, not to exceed two paragraphs, may be quoted without explicit permission provided that full credit, including (C) notice, is given to the source. 


\title{
About the Center for Retirement Research
}

The Center for Retirement Research at Boston College, part of a consortium that includes parallel centers at the University of Michigan and the National Bureau of Economic Research, was established in 1998 through a grant from the Social Security Administration. The Center's mission is to produce first-class research and forge a strong link between the academic community and decision makers in the public and private sectors around an issue of critical importance to the nation's future. To achieve this mission, the Center sponsors a wide variety of research projects, transmits new findings to a broad audience, trains new scholars, and broadens access to valuable data sources.

\author{
Center for Retirement Research at Boston College \\ Hovey House \\ 140 Commonwealth Avenue \\ Chestnut Hill, MA 02467 \\ phone: 617-552-1762 fax: 617-552-0191 \\ e-mail: crr@bc.edu \\ www.bc.edu/crr
}

\author{
Affiliated Institutions: \\ The Brookings Institution \\ Massachusetts Institute of Technology \\ Syracuse University \\ Urban Institute
}




\begin{abstract}
This study examines the effect of work-limiting disabilities on the likelihood of divorce. Theoretically, the effect depends on the disability hazard at the time of onset and the impact of disability on marital value. The theory therefore implies, based on a set of empirically supported premises, that the effect of disability on divorce should decrease with age, increase with education, and increase with disability severity. Data from the Survey of Income and Program Participation support these predictions. The effect of a work-preventing disability is greatest among young, educated males, increasing the divorce hazard by 13.3 percentage points.

JEL Codes: J12, H55
\end{abstract}




\section{Introduction}

The “Divorce Revolution” in the U.S., marked by a surge in divorce in the 1960s, heightened interest among researchers, policymakers, and social commentators in the determinants of marriage formation and dissolution. While many attributed the rise in divorce to new cultural preferences, economists sought to explain divorce using existing choice theory. The theoretical models of marriage and divorce - developed by Becker (1974) and Becker, Landes, and Michael (1977), respectively - motivate much of the research in economics. According to Becker, marriage occurs if the joint benefit of marriage exceeds the combined benefit of remaining single. Conversely, divorce occurs if the joint benefit of separation exceeds the combined benefit of remaining married. The frameworks together imply that marriage yields a sufficient benefit at the time of union, but its value may decline over the course of a marriage to precipitate divorce.

To test this framework of marital instability, economists examine whether relative declines in the value of marriage increase the likelihood of divorce. But since marital value is difficult to quantify objectively, researchers rely on observable measures that likely determine marital value such as earnings and health. If so, changes in earnings and health over the course of a marriage should increase the likelihood of divorce.

This study adds to the literature on marital dissolution by examining the association between disability onset and divorce. According to the existing framework of marital instability, the effect of disability on divorce depends on two factors. The first factor is the incidence, or hazard rate, of disability at the time of onset. Intuitively, the likelihood of a disability is already incorporated in the expected divorce decision, so anticipated disabilities should impact divorce less than unanticipated disabilities. The second factor is the effect of disability on marital 
quality, measured by the difference in marital value between disabled and nondisabled states. As the impact of disability on marital value increases, so too does the likelihood of divorce.

As a test of the divorce model's implications, I estimate the association between disability and divorce by age, education, and disability severity. The incidence of disability should increase with age, decrease with education, and decrease with disability severity. And the impact of disability on marital value should decrease with age, increase with education, and increase with disability severity. Thus, the association between disability and divorce should decrease with age, increase with education, and increase with disability severity.

I test the theoretical conjectures on disability and divorce, as well as the premises upon which they are based, using data from the Survey of Income and Program Participation (SIPP). To estimate disability incidence and the association between disability and divorce, I use retrospective data on marriage and disability contained in topical module two of the SIPP. To gauge the effect of disability on marital value, I use longitudinal earnings records merged to the SIPP - the dynamic effect of disability on earnings serves as a proxy for the effect of disability on the value of marriage. The analysis is conducted separately for males and females with an initial focus on males.

The SIPP data strongly support the conjectures regarding disability incidence, marital value, and divorce. First, among males, disability incidence is lower among the young and more educated, and disabilities that completely prevent work are less common than disabilities that only prevent work. Second, the impact of disability onset on long-run earnings is greatest among the young, more educated, and more severely disabled. In fact, among the oldest age category, the long-run effect of disability on earnings is statistically insignificant. And finally, the 
association between disability and divorce is greatest among young, educated males whose disabilities completely prevent work.

The SIPP data reveal similar but less striking patterns among females: the gradient of disability incidence by age and education is flatter; the dynamic effect of disability on earnings is less severe; and the association between disability and divorce is insignificant.

The results provide new insight into the divorce decision. Lead studies in the literature find that divorce is associated with shocks to earnings capacity. However, earnings shocks themselves do not affect divorce; they affect divorce indirectly through their impact on marital value and outside alternatives. To support this distinction, Charles and Stephens (2004) estimate the association between divorce and explicit negative earnings shocks and find that, although disability and job loss affect earnings similarly, only job loss is associated with divorce. The different results may reflect, as suggested by the authors, that job loss reveals more information about spousal quality than disability. (The authors also suggest that the social cost of divorcing a disabled spouse is greater than the cost of divorcing a recently unemployed spouse.) However, the results from this study reveal that aggregate-level estimates - the empirical strategy of Charles and Stephens - may obscure the effects of explicit earnings shocks on divorce, especially if the shocks occur predominately among those whose divorce decision is changed the least (in particular, disability onset among the elderly). This study shows that disability not only affects divorce in some cases, but does so in a manner consistent with theoretical predictions.

\section{Background}

\section{A. Conceptual Framework and Empirical Studies}


The seminal works by Becker (1974) and Becker, Landes, and Michael (1977) provide a conceptual framework of marriage and marital instability. According to the latter study, divorce occurs when the combined benefit of separating exceeds the joint benefit of remaining married. This proposition is straightforward if the welfare of each partner independently improves upon separation. The less obvious case occurs when, prima facie, one partner loses welfare while the other gains. In such a case, the gain must exceed the loss, so the latter can compensate the former to the point that both partners agree to separate. This framework of marital instability follows directly from Becker’s (1974) model of marital formation: marriage occurs if and only if the joint benefit of marriage exceeds the joint benefit of remaining single.

Based on the theoretical models of marital formation and dissolution, Becker, Landes, and Michael (1977) raise an obvious question: How do the gains from marriage and separation change to explain the observed patterns of divorce? The authors discuss two factors. The first factor is initial match quality. Intuitively, a union between any two individuals yields a level of match quality, and only couples whose match quality exceeds a minimal threshold will result in marriage. But as search costs to finding a good mate increase, or traits for a successful match become harder to find, the minimal level of match quality declines. Lower quality marriages, in turn, are more susceptible to divorce.

The second factor is uncertainty in marital value. Marital value is dynamic, determined by a stream of benefits that, at the time of union, are uncertain. Factors both internal and external to the marriage may lead to unanticipated changes in marital value, changes referred to as "shocks" in the literature. In theory, these shocks affect the value of marriage and the value of outside alternatives such that any shock - for better or for worse - increases the likelihood of 
divorce. The two factors together suggest that the highest at-risk group for divorce is low-quality marriages that face a high degree of uncertainty.

The economic literature on divorce focuses more on uncertainty in marital quality rather than poorly matched marriages. ${ }^{1}$ But shocks to marital quality can be difficult to quantify objectively, so some researchers rely on observable changes in earnings, employment status, and health as indicators of marital quality shocks.

Two leading studies focus on shocks to earnings. In the first study, Becker, Landes, and Michael (1977) measure earnings shocks as the absolute difference between actual and predicted earnings. ${ }^{2}$ They find that unexpected earnings have a positive, though small and insignificant, effect on the likelihood of divorce, results consistent with their model of marital instability. But the authors estimate earnings shocks using cross-sectional data, making it difficult to isolate earnings shocks from one’s unobservable quality as a mate - a point raised by Weiss and Willis (1977). Without convincing controls for spousal quality, cross-sectional data and analysis may yield biased results.

The second study, by Weiss and Willis (1997), addresses the limitations of crosssectional data by using data that are longitudinal - the National Longitudinal Study of the High School Class of 1972. The authors use within-person deviations in expected earnings capacity as a measure of shocks to earnings, a strategy that implicitly controls for unobservable quality that remains fixed. The authors find that an increase in male earnings capacity decreases the likelihood of divorce, but an increase in female earnings capacity increases the likelihood of divorce.

\footnotetext{
${ }^{1}$ Weiss and Willis (1997) measure how the effect of earnings shocks on divorce varies by match quality.

${ }^{2}$ Expected earnings are estimated from a regression of earnings on a set of observable factors: years of schooling, years of work experience, marital status, and weeks worked. Expected earnings are defined as the predicted values from this regression.
} 
These two studies provide path-breaking analysis on marital dissolution; but the extent to which earnings shocks come as a surprise, as well as the information they convey about one's suitability as a mate, remains underexplored. In a very insightful study, Charles and Stephens (2004) examine the likelihood of divorce following different types of negative earnings shocks. The authors' main insight is that although different shocks may have similar adverse effects on earnings, some shocks convey more information about one's suitability as a mate than others. Charles and Stephens present evidence to support this insight. The authors' main finding is that job displacement and disability have similar effects on earnings, but only job displacement is associated with divorce. Moreover, the association between job loss and divorce is driven mainly by layoffs and not plant closings. As one of several explanations, the authors suggest that disability may be perceived as "bad luck" and therefore uninformative about one’s spousal quality. Job loss, on the other hand, is a reflection of one's discipline and temperament - layoffs more so than indiscriminate plant closings.

\section{B. Disability and Marital Instability}

In contrast to Charles and Stephens (2004), who estimate how different types of shocks affect divorce among all marriages, I examine how the same type of shock - disability onset affects divorce across marriages. To guide the analysis of disability and divorce, I return to the dynamic divorce model of Weiss and Willis (1997) and Charles and Stephens (2004), a model based on the original insights of Becker (1974) and Becker, Landes, and Michael (1977). In the model, the lifetime wealth resulting from a union between individuals $i$ and $j$ is given by the function $\phi\left(g_{t}, g_{t}\right)$, where $g_{h}$ is a disability status indicator that equals one if person $h$ is disabled and zero otherwise. A disability presumably decreases marital wealth by affecting the 
ability to earn income and to produce in the home. The terms $A_{t}\left(g_{t}, g_{t}\right)$ and $A_{t}\left(g_{t}, g_{t}\right)$ represent the value of the next best alternative to marriage for individuals $i$ and $j$, respectively, net the cost of divorce. According to Becker's (1974) original insights, marriage occurs if and only if the joint surplus of marriage is weakly positive: $\phi 2 A_{t}+A_{j}$.

The total lifetime wealth of individuals $i$ and $j$, conditional on being married, is given by the function,

$$
\phi\left(g_{t}, g_{t}\right)=V\left(g_{t}, g_{t}\right)+\Omega E_{t}\left\{\max \left[\phi^{*}\left(g_{t}, g_{t}\right), A_{t}^{*}\left(g_{t}, g_{t}\right)+A_{i}^{*}\left(g_{t}, g_{t}\right)\right]\right\}
$$

where $V\left(g_{t}, g_{t}\right)$ is the current wealth from marriage, and the second term is the expected, combined wealth in the future. Future wealth is equal to the value of marriage or divorce next period, whichever is greater, discounted by the factor $\Omega$. The marriage is expected to dissolve next period if $E_{t}^{*}\left\{A_{t}^{\prime \prime}\left(g_{t}, g_{t}\right)+A_{t}^{* \prime}\left(g_{t}, g_{t}\right)\right\}$ exceeds $E_{t}^{\prime}\left\{\phi^{\prime \prime}\left(g_{t}, g_{t}\right)\right\}$.

Disability onset could alter the realized marital dissolution decision from the expected decision by decreasing both the value of marriage and the value of outside alternatives. Without further constraints, a reduction in both terms implies that the effect of disability on divorce is ambiguous. However, Becker, Landes, and Michael (1977) contend that the decline in marital value would exceed the decline in the value of outside alternatives, so the effect of disability on the probability of divorce is nonnegative. ${ }^{3}$

Assuming that the effect is nonnegative, its magnitude, if any, remains unclear. The effect depends on the difference between expected and realized marital wealth when a disability occurs. For ease of characterization, three assumptions are made: no one is initially disabled; the

\footnotetext{
3 “A larger deviation between actual and expected values, such as actual and expected earnings or fecundity, raises the probability of dissolution. The reason is that the gain from becoming divorced from marrying someone else increases by more than the gain from remaining married to the same spouse (Becker, Landes, and Michael, 1977).”
} 
likelihood that person $j$ becomes disabled is zero; and the incidence of disability for person $i$ is defined as $g_{t}$. Expected marital wealth in this case is

$$
g_{t} \phi^{\prime \prime}(1,0)+\left(1-g_{t}\right) \phi^{\prime \prime}(0,0)
$$

and if person $i$ actually becomes disabled, realized marital wealth is $\phi^{m}(1,0)$. Thus, the difference in the expected marital wealth and realized marital wealth when person $i$ becomes disabled is given by,

$$
\left(1-g_{t}\right)\left[\phi^{\prime \prime}(0,0)-\phi^{\prime \prime}(1,0)\right],
$$

which is positive since $0 \mathscr{S}_{t} \mathscr{S}_{1} 1$ and if $\phi^{m}(0,0)>\phi^{m}(1,0)$. According to Becker, Landes, and Michael (1977), the impact of disability on divorce increases with this term.

Two implications follow. First, the effect of disability on divorce depends on the ex ante incidence, or hazard rate, of disability onset $g_{t}$. Intuitively, the expected divorce decision already reflects the likelihood of disability, so an anticipated disability should alter less the realized dissolution decision from the expected decision. And second, the effect of disability on divorce increases with its adverse impact on the value of marriage, measured as the difference in marital value between disabled and nondisabled states. According to the equation above, these two effects interact with one another, so the effect of disability on divorce is greatest when the disability has a substantial effect on the value of marriage and is largely unanticipated.

\section{Methodology}

\section{A. Data}

The main data source for the empirical analysis is the Survey of Income and Program Participation (SIPP). The SIPP is a nationally representative, longitudinal survey designed to 
measure monthly changes in income and program participation. The basic demographic information for this study come from the core data file in wave two, reference month four (the eighth month of the panel). Information on disability and marriage comes from wave two topical module data. To increase the sample size, I pool SIPP data from panel years 1990, 1991, 1992, 1993, and 1996. I initially focus on males only.

The disability and marriage data are retrospective. In regards to disability, respondents first report whether they have a health condition that limits the kind or amount of work they can do and, if so, the month and year in which the work limitation began. Work-limited respondents then report whether the condition prevents them from working at a job or business and, if so, the month and year in which they became unable to work. The SIPP measure of disability, defined by the ability to work, is similar to the disability question used by Charles and Stephens (2004) from the Panel Survey of Income Dynamics. Since the precise timing of the work limitation or prevention is essential for the empirical analysis, observations are dropped if the dates of disability onset are missing. ${ }^{4}$

In regards to marriage, respondents report the number of previous marriages and the dates of marriage, separation, and divorce. The module only collects marriage formation and dissolution information for up to three marriages, so individuals who report four or more marriages are dropped from the sample. Since the empirical objective is to measure the effect of disability on divorce, individuals who were never married at the time of wave 2 are dropped from the sample as well.

\footnotetext{
${ }^{4}$ I also drop observations if the work-prevention date occurs before the work-limitation date since it is inconsistent with the order of the survey questions - the work-prevention question is asked if and only if one reports being worklimited. I also omit observations that appear in the topical module data but not in the core data file, which happens to occur in panels 1990 through 1993.
} 
The empirical analysis is based solely on retrospective data. I do not take advantage of the longitudinal SIPP data for two reasons. First, some SIPP panels are less than three years in length. As such, the incidence of disability over the course of a panel is small; and if divorce due to disability occurs with a reasonable lead or lag, all divorces that result from disability onset may not be observed. Second, and more importantly, sample attrition appears to be an issue with SIPP data, posing serious econometric problems if attrition is related to life altering events such as disability onset and divorce. ${ }^{5}$

\section{B. Empirical Strategy}

The empirical objective is to examine the potentially heterogeneous effect of disability on divorce. According to the model above, the impact of disability on divorce depends on the disability hazard at the time of onset, which is relatively easy to estimate, and the impact of disability on marital value, which is more difficult to quantify.

As a less parametric alternative, I examine the association between disability and divorce along three dimensions: age of disability onset, educational attainment, and the severity of the disabling condition. The disability hazard should increase with age, decrease with educational attainment, and decrease with disability severity. And the effect of disability on marital value should decrease with age, increase with educational attainment, and increase with disability severity. Based on these premises, the likelihood of divorce should decrease with age, increase with educational attainment, and increase with disability severity.

The first part of the analysis provides empirical support for the aforementioned premises. In particular, I estimate the incidence of divorce and the dynamic effect of disability on earnings by age, educational attainment, and disability severity. The effect of disability on earnings is an

\footnotetext{
${ }^{5}$ According to Slud and Bailey (2006), attrition over the life of a SIPP panel is approximately 30 percent by the end of wave 12 .
} 
indicator of its effect on marital value, similar in spirit to Becker, Landes, and Michael (1977) and Willis and Weiss (1997). In the second part of the empirical analysis, I estimate the effect of disability on the divorce hazard along the same dimensions.

A natural concern with self-reported disability stat is that they are subjective, so respondents may only consider types of work to which they are accustomed, or are reasonably qualified to do, to determine whether they are work disabled. As a result, the prevalence of work-limiting disabilities by education and age may not fully reflect differences in health across these groups and certainly reflect expected engagement in the labor market. But if the effect of disability on labor force participation is the main mechanism by which disability leads to divorce, and a respondent's own labor market expectations align with his or her spouse's, then subjective measures of work-limiting disabilities are arguably more appropriate than objective measures in the context of disability and divorce.

\section{Theoretical Premises}

\section{A. Disability Hazard}

Using data from the SIPP, I calculate work-limiting disability hazards over a three-year period. The sample is conditioned on males who are married and not work-limited exactly 36 months prior to topical module two; the disability hazard is defined as the percent of these individuals who become work limited by the date of the survey. (Summary statistics are not reported for this sample since it is not the primary sample of the analysis.) The hazard rates are calculated separately by two education categories and three age categories, the latter based on one's age 36 months prior to topical module two. The education categories are high school diploma or less (“Low Education”) and some college or more (“High Education”), and the age 
categories are 29 to 40, 41 to 52, and 53 to 64 . I first calculate the hazard rate of any worklimiting disability - including both work-limiting and work-preventing disabilities - and then the hazard rate of work-preventing disabilities only. ${ }^{6}$

The estimated rates of any disability, presented in the left panel of Table 1, confirm that that the hazard increases with age and decreases with education. The gradient by age appears to be steeper among more educated males: the relative risk of work limitation onset by age (ages 53 to 64 versus age 29 to 40 ) among less and more educated males is 2.68 and 3.43, respectively. Additionally, the gradient by education appears to be steeper among younger males: the relative risk of work limitation onset by education (low versus high education) at ages 41 to 52 and 53 to 64 is 3.15 and 1.87 , respectively.

The hazard-rate pattern by age and education is similar when the work-limited sample is restricted to work-preventing disabilities. The hazard estimates, presented in the right panel of

Table 1, decrease with education and, within each education group, increase with age.

Moreover, the panels together indicate that, in comparison to work-limiting disabilities, workpreventing disabilities are less common. The one exception is among less educated males at ages 53 to 64: the incidence of disabilities that only limit work and entirely prevent work is 3.38 percent and 4.52 percent, respectively.

\section{B. Marital value}

The second set of premises pertains to the adverse effect of disability on marital value. Ostensibly, expected marital value depends on the assumed responsibilities of each partner, responsibilities that may be difficult to perform following disability onset. An obvious responsibility is one's expected participation and success in the formal labor market. Therefore,

\footnotetext{
${ }^{6}$ Over the 36 month period, a person may become both work-limited and work-prevented. By construction, individuals who become work-prevented necessarily become work-limited on or after the work-limitation date.
} 
as an indicator of the effect of disability on marital value, I examine the dynamic effect of disability on earnings.

To perform the analysis, I impose four main restrictions to the SIPP data in addition to those discussed in section III subsection A. The first three restrictions, discussed in more detail in the Appendix, pertain to the dates of disability onset and marriage relative to the date of topical module two. The most consequential restriction is a condition of marriage: the sample is restricted to disabled males who were married 18 months prior to disability onset or nondisabled males who were married 54 months prior to topical module 2. These restrictions are more relevant for the examination of disability and divorce in the next section, but are imposed here for uniformity. A detailed discussion of these restrictions and the corresponding sample are provided in Appendix A.

The fourth main restriction is that the SIPP data be matched to longitudinal earnings data contained in the Detailed Earnings Record (DER). The DER is an administrative data file maintained by the Social Security Administration that reports earnings - the sum of taxable wage earnings, taxable self-employment earnings, and income deferred to 401(k) or similar type accounts - on an annual basis from 1978 to 2004. All earnings values are adjusted to 2004 levels using an average wage index. The derivation of the DER matched data are given in Appendix B.

I first compare raw trends in annual earnings between the recently disabled and nondisabled. Trends for both groups are centered on period zero and extend seven calendar years before and after this date. For the disabled, I define period zero as the calendar year in which the disabling condition occurs. For the nondisabled, I define period zero as the calendar year in which topical module two occurs. Since disability status is known only up to the survey date, the earnings trends of the nondisabled could reflect disabilities that occur after period zero. 
Figure 1 illustrates trends in average annual earnings by three disability groups: the nondisabled, the work-limited only, and the work-prevented only. ${ }^{7}$ The first notable observation is that pre-disability earnings are lower among the disabled groups relative to the nondisabled group. Second, both disability groups exhibit a fall in earnings at the time of disability onset; the drop is greater for those who become completely unable to work, most of whom report zero or near zero income following disability onset. Third, the level of earnings among the disabled does not appear to recover following disability onset. ${ }^{8}$ And finally, the earnings of the nondisabled appear to decline slightly after period zero, a trend that may reflect the onset of work-limiting conditions thereafter.

To examine the final point, Figure 2 graphs trends in earnings by disability status and period-zero age. Each panel corresponds to a different age category: 29 to 40, 41 to 52, and 53 to 64. For brevity, the work-limited sample is represented by a single group. As indicated, the decline in nondisabled earnings after period zero, highlighted in Figure 1, is driven primarily by the oldest age category. This suggests that earnings prospects among the aged are declining regardless of disability onset status at period zero. In contrast, earnings among the young and nondisabled continue to rise following period zero, increasing the long-run difference in earnings between the disabled and nondisabled samples.

Figure 3 presents earnings trends by educational attainment and disability status. As shown, the difference in pre-disability earnings between the disabled and nondisabled is greater among the more educated. And although the disabled samples at both levels of education exhibit a precipitous decline in earnings at the time of disability onset, the long-run earnings gap

\footnotetext{
${ }^{7}$ For the earnings analysis presented here, as well as the disability and divorce analysis in the next section, individuals are defined as work-prevented if they report becoming work-prevented within 12 months of becoming work-limited.

${ }^{8}$ Charles (2003) finds evidence of earnings recovery after disability onset among males whose disabilities are least severe.
} 
between the disabled and nondisabled samples appears to increase only among the more educated.

To quantify the effect of disability on longitudinal earnings, I use a fixed-effect regression model that controls for age and year effects. The preferred specification, consistent with previous studies in the disability and earnings literature, is given by:

$$
Y_{t t}=\alpha_{t}+\gamma_{t}+\beta X_{t t}+\Sigma_{T} \theta_{T}^{N} P_{t \omega T}+\Sigma_{T} \theta_{T}^{D} P_{t t r} D_{t}+\varepsilon_{t t}{ }^{9}
$$

The subscripts $i$ and $t$ reference the individual and year, respectively. The variable $Y_{t t}$ is earnings; $\alpha_{i}$ is an individual fixed effect; $\gamma_{t}$ is a year fixed effect; and $X_{t t}$ are time-invariant characteristics (age and age squared). The variable $\boldsymbol{P}_{t \text { tr }}$ is a period indicator; it equals one when individual $i$ in year $t$ is $\tau$ periods from period zero and equals zero otherwise. The variable $D_{t}$ is a disability sample indicator; it equals one if individual $i$ becomes disabled at period zero and equals zero otherwise. The error term $\varepsilon_{t t}$ is clustered by person.

The coefficient $\Theta_{E}^{D}$ is interpreted as the average, within-person effect of disability on earnings levels exactly $\tau$ periods from the date of disability onset. The range of $\tau$ is six years before and seven years after period zero; the seventh year before period zero is the "left-out" period. The sample includes both disabled and nondisabled observations; the nondisabled observations help to identify the effects of year, age, and period. To determine whether the disability coefficients vary by age and education, I restrict both the disabled and nondisabled samples along these dimensions. ${ }^{10}$

\footnotetext{
${ }^{9}$ This earnings equation is similar to Charles (2003) and Meyer and Mok (2008). In contrast to Charles, earnings are expressed in levels to avoid discarding zero earnings. In contrast to Meyer and Mok, period effects are included for the nondisabled, accounting for the mechanical relationship between period effects and earnings since disability status is known only up to period zero.

${ }^{10}$ Based on Figures 1 to 3, the period effects for the disabled and nondisabled samples differ by age and education. There are two methods to account for these differences. The first is a single regression with full interactions of the
} 
Table 2 presents regression results for six sample specifications based on age and educational attainment. The disabled observations contain both work-limited and workprevented individuals. As reported, the impact of disability on earnings levels is greatest among the young and more educated. By the seventh year after disability onset, young, educated men earn approximately \$40,000 less (in 2004 dollars) than they would have earned had they not become disabled. ${ }^{11}$ In contrast, the long-run effects among the oldest age categories are statistically insignificant; a result not reflecting a recovery in earnings among the disabled, but rather a decline in earnings among the nondisabled.

\section{Estimates of the Divorce Hazard}

\section{A. Baseline Estimates}

According to the conceptual framework of marital instability, the effect of disability on divorce should decrease with the disability hazard and increase with the effect of disability on the value of marriage. These predictions, combined with the empirical analysis presented in section IV, imply that the association between disability and divorce should decrease with age, increase with education, and increase with disability severity. ${ }^{12}$

I test these implications by comparing divorce hazards between the disabled and nondisabled by age, education, and disability severity. I use the same SIPP sample in section IV subsection B without the additional restriction that the data be matched to the DER. The divorce hazard is defined as the percent of individuals who become divorced over a 36-month period

period effects with age and education. The second is separate regressions estimated from samples restricted by age and education. For ease of interpretation, I report results from the second method.

${ }^{11}$ Meyer and Mok (2008) estimate an average decline of \$29,389 (in 2005 dollars) in the seventh year following disability onset among a sample of chronically and severely disabled males.

${ }^{12}$ Research on self-reported marital quality, a more direct but less objective measure than earnings, also support the premise that health shocks have a greater effect on marital quality among the young (Yorgason, Booth, and Johnson 2008). 
conditional on being married in the month before the period begins. For the disabled sample, the period begins 17 months before disability onset and 18 months after disability onset. This specification, which allows divorce to predate disability onset, accounts for conditions that are expected to limit work, but do not limit work at the time of divorce. ${ }^{13}$ For the nondisabled, the period begins 53 months before topical module two and ends 18 months before topical module two. Consistent with the literature on marital instability, divorce is defined as separation or divorce, whichever occurs first. The empirical specifications and data restrictions are discussed further in the Appendix A.

The first set of divorce hazards are presented in Table 3. The left and right panels correspond to the low and high education samples, respectively. Within each panel, the rate of divorce is presented separately by age and disability status - the disabled includes both worklimiting and work-preventing disabilities. The difference in divorce rates between the disabled and nondisabled are reported in the third columns of each panel.

The estimates in Table 3 support the theoretical conjectures with regards to age and education. As shown, the divorce rates among the disabled are generally greater than the divorce rates of the nondisabled, a difference that increases with education and decreases with age. The greatest difference is among the young and more educated: a statistically significant difference of 5.2 percentage points. By ages 53 to 64 , the estimated effect of disability on divorce is negligible and insignificant.

The data also support the theoretical conjectures with respect to disability severity. In Table 4, I present similar divorce estimates as Table 3, but restrict the disabled sample to work-

\footnotetext{
${ }^{13}$ Meyer and Mok (2008) conclude that disability is partially, but imperfectly, predictable in the short-run. This conclusion is based on their finding that the drop in earnings around the time of disability onset occurs shortly before the condition limits work, a finding also reported by Stephens (2001) and Charles (2002). Since the value of marriage reflects future expectations, new information about future work limitation could affect the current divorce decision, allowing for divorce to predate the work limitation.
} 
limiting disabilities only. As shown, the rate of divorce is greater among individuals who become unable to work, increasing the difference in divorce rates between the disabled and nondisabled samples. Similar to Table 3, the difference in divorce rates by disability status increases with education and decreases with age. The greatest difference in divorce rates occurs among the young and more educated: a statistically significant difference of 20.2 percentage points.

\section{B. Controls for Marital Quality}

The empirical results support the main thesis of the paper, but the empirical analysis and interpretation omits another important determinant of divorce: initial marital quality. According to divorce model of Becker, Landes, and Michael (1977), divorce occurs when the joint value of marriage falls below the value of outside alternatives. Thus, the effect of disability on divorce depends not on the change in marital value, but whether the decline in value from its initial level is sufficient to trigger divorce.

An empirical consideration, then, is whether disability incidence is negatively associated with latent marital quality within age and education groups. If so, the observed divorce rate among the disabled may be greater than the counterfactual divorce rate among the nondisabled had they become work-limited. Additionally, and more importantly, marital quality may vary systematically by age, education, and disability status. For example, the low rates of divorce among the aged may reflect higher marital quality among them. If so, the graded association between disability and divorce by age and education may overstate the gradient had across-group marriage quality remained constant. ${ }^{14}$

\footnotetext{
${ }^{14}$ It is also plausible that the association between disability incidence and latent marital quality (within age and education groups) could increase with education and decrease with age. If so, the graded association between disability and divorce by age and may overstate the gradient had within-group marriage quality remained constant.
} 
To control for marriage quality, I estimate models of divorce that include both disability status and marital characteristics. The estimation equation is given by

$$
\left.D=F\left[\alpha+\beta L+\sum_{a=2} \gamma_{a} A_{a}+\delta E+\sum_{a=2} \lambda_{a} A_{a} E+L\left(\sum_{a=2} \pi_{a} A_{a}+\theta E+\sum_{a=2} \rho_{a} A_{a} E\right)+\eta X\right] \cdot\right]
$$

where D is the conditional likelihood of divorce; F[.] is the conditional likelihood function; L, disability onset status; A, two age categories; E, education; and X, a vector of marital characteristics. (Subscripts are omitted.) The two age categories are 41 to 52 and 53 to 64; the left out group is age 29 to 40 . The education variable is high school or less; the left out group is some college or more. Marital characteristics include an indicator for a first marriage, age at marriage, and marriage tenure. Since the sample is conditioned on married, nondisabled persons at the start of the 36-month period, the conditional probability estimates are interpreted as the hazard rate of divorce. ${ }^{15}$

The empirical results from the linear probability model are presented in the left panel of Table 5. In the first two columns, the disabled sample includes both work-limiting and workpreventing disabilities. Marital characteristics are excluded in the first column and included in the second column; the first column corresponds to the figures in Table 3. (The standard errors in Table $\mathbf{3}$ are smaller since the disabled and nondisabled samples are considered independent.) The inclusion of marital characteristics, reported in the second column, decreases the magnitude and statistical significance of the estimated effects, suggesting that marital quality is correlated to some extent with disability incidence. ${ }^{16}$ However, the graded effect by age and education remains robust.

\footnotetext{
${ }^{15}$ Charles and Stephens (2004) also estimate the hazard rate of divorce using probability models and an appropriately conditioned sample.

${ }^{16}$ The variable indicating whether the marriage is a first drives much of the decline in the effect of disability on divorce.
} 
The third and fourth columns report results after limiting the disabled sample to workpreventing disabilities only. Marital characteristics are excluded from the specification in the third column and included in the fourth column; the third column corresponds to the figures in Table 4. As shown, the inclusion of marital characteristics decreases the estimated effects of disability on divorce, but the effect among young, educated males remains statistically significant at 13.3 percentage points.

The empirical results from the probit model are presented in the right panel of Table 5. For ease of interpretation, the probit estimates are reported as marginal effects. As shown, the probit model yields the same substantive conclusions as the linear probability model. First, within each age and education category, the estimated effect of disability on divorce is greater among the most severe cases of disability. Second, the inclusion of marital characteristics decreases the estimated effect for all age and education categories. And finally, within each sample specification, the effect of disability on divorce is generally greater among the young and more educated.

\section{Disability, Earnings, and Divorce among Females}

The patterns of disability, earnings, and divorce among males are also evident among females, but the patterns among females are not as salient. First, the disability hazard does increase with age and decrease with education, but the gradients are relatively moderate (not shown). Second, disability onset is associated with a decline in earnings, but the decline is less severe (not shown). Third, recently disabled females are more like to divorce compared to the nondisabled, but the difference in divorce rates is smaller. And finally, and the difference in divorce rates between the disabled and nondisabled does decrease with age and increase with education, but the gradients are less steep. Table 6, which presents divorce model estimates for 
females similar to Table 5 for males, reveals that although the effect of disability on divorce is greatest among young females, the difference is statistically insignificant.

Several factors may explain the different results between males and females. The first set of explanations stem from empirical observation. According to theory, if the gradients of disability incidence and earnings by age and education are steeper among males compared to females - a pattern supported by the data - then so too should the gradient of divorce. The second set of explanations stem from the theoretical model of marital instability. According to the model, the likelihood of divorce depends on marital quality and the value of outside alternatives, net the cost of divorce. Thus, the effect of disability on marital quality may differ between males and females, or the social stigma of divorcing a disabled female is greater than divorcing a disabled male. The contribution of these factors to the observed patterns of divorce remains unknown.

\section{Discussion and Conclusion}

According to the economic framework of marital instability, the effect of disability on the likelihood of divorce is not uniform across marriages, but varies with both the expected incidence of disability at the time of onset and the impact of disability on marital value. Based on a set of empirically supported premises, the model implies that the effect of disability on divorce should decrease with age, increase with education, and increase with disability severity. The data support these predictions.

This study also highlights a consideration for future research. When examining the effect of explicit shocks and marital dissolution, one should consider how shock incidence varies with the effect of the shock on divorce. This study shows in particular that disability incidence is 
greatest, and the effect of disability on divorce is the smallest, among the aged. As a result, population-wide analysis may obscure the potentially heterogeneous effects of shocks on divorce, effects that are important to the broader understanding of the divorce decision.

The results also have implications for the insurance benefits of interpersonal relationships, an oft-cited advantage of marriage. For example, Di Tella and MacCulloch (2002) consider the benefits of interpersonal relationships during unemployment spells; Weiss (1994) characterizes spouses as creditors when faced with financial hardship; Kotlikoff and Spivak (1981) model the family as an informal annuity market to insure against unexpected longevity; and Arnott and Stiglitz (1991) highlight the ameliorating support of friends and families after an accident. An underexplored issue is whether arrangements of informal insurance are sustainable through times of adversity, even though the marriage itself is not.

This study also raises interesting questions regarding formal insurance. If the relationship between disability and divorce reflects the effect of unexpected earnings losses, then more generous formal insurance, either public or private, may reduce the effect of disability on divorce by replacing lost earnings. However, formal disability insurance may actually increase divorce rates by making the alternatives to marriage more attractive: disability benefits may discourage work and encourage divorce among individuals who would otherwise work and remain married. The effect of formal disability insurance generosity on the divorce rates of the disabled is an intended direction for future research. 


\section{Table 1}

Three-Year Disability Hazards among Males by Education, Age, and Disability Severity

\begin{tabular}{lccccc}
\hline & \multicolumn{2}{c}{ Any Disability } & & \multicolumn{2}{c}{ Work-Preventing Disabilities } \\
\cline { 2 - 3 } \cline { 5 - 6 } Age & Low Education & High Education & & Low Education & High Education \\
\cline { 2 - 3 } $29-40$ & 2.95 & 1.23 & & 1.09 & 0.28 \\
& $(0.20)$ & $(0.11)$ & & $(0.12)$ & $(0.053)$ \\
& {$[7250]$} & {$[9787]$} & & {$[7250]$} & {$[9787]$} \\
& & & & 1.89 & 0.39 \\
$41-52$ & 4.82 & 1.53 & & $(0.18)$ & $(0.074)$ \\
& $(0.29)$ & $(0.15)$ & & {$[5640]$} & {$[7118]$} \\
& {$[5640]$} & {$[7118]$} & & & \\
$53-64$ & 7.91 & 4.23 & & 4.52 & 1.61 \\
& $(0.41)$ & $(0.34)$ & & $(0.31)$ & $(0.21)$ \\
& {$[4411]$} & {$[3542]$} & & {$[4411]$} & {$[3542]$} \\
\hline
\end{tabular}

Note: The sample comes from pooled SIPP data (panel years 1990, 1991, 1992, 1993, and 1996). Age is based on one's age 36 months prior to topical module 2. "Low education" is defined as a high school diploma or less; "High education" is defined as some college or more. Standard errors are in parentheses; sample sizes are in brackets. Sample weights were used. See Appendix for further details. 
Table 2

Dynamic Effect of Any Disability on Earnings among Males by Education and Age

\begin{tabular}{|c|c|c|c|c|c|c|}
\hline \multirow{3}{*}{$\begin{array}{c}\text { Years Since } \\
\text { Disability Onset }\end{array}$} & \multicolumn{3}{|c|}{ Low Education } & \multicolumn{3}{|c|}{ High Education } \\
\hline & \multirow[t]{2}{*}{$29-40$} & \multirow[t]{2}{*}{$41-52$} & \multirow[t]{2}{*}{ 53-64 } & \multirow[t]{2}{*}{$29-40$} & \multirow[t]{2}{*}{$41-52$} & \multirow[t]{2}{*}{ 53-64 } \\
\hline & & & & & & \\
\hline \multirow[t]{2}{*}{-6} & -0.21 & 0.34 & -0.85 & -0.30 & -1.1 & 2.0 \\
\hline & (1.1) & $(1.2)$ & (1.4) & (1.9) & (2.7) & $(2.6)$ \\
\hline \multirow[t]{2}{*}{-5} & 0.81 & 0.45 & 0.83 & -3.0 & 0.47 & 2.5 \\
\hline & (1.5) & $(1.6)$ & (1.7) & (2.2) & (2.8) & (3.7) \\
\hline \multirow[t]{2}{*}{-4} & 2.3 & -0.30 & 0.0 & -7.5 & -3.5 & 7.6 \\
\hline & (1.7) & (1.7) & (2.0) & $(2.8)^{* *}$ & (3.2) & $(5.4)$ \\
\hline \multirow[t]{2}{*}{-3} & 1.5 & 0.31 & 1.2 & -8.5 & -3.7 & 9.2 \\
\hline & (1.8) & (1.9) & (2.7) & $(3.0)^{* *}$ & (3.7) & $(5.5)$ \\
\hline \multirow[t]{2}{*}{-2} & 0.54 & 1.1 & 1.2 & -11.7 & -7.5 & 8.7 \\
\hline & (1.9) & (2.1) & (2.4) & $(4.3)^{* *}$ & (4.1) & (5.6) \\
\hline \multirow[t]{2}{*}{-1} & 0.0 & -0.20 & 1.4 & -12.2 & -12.1 & 2.4 \\
\hline & $(2.21)$ & $(2.2)$ & (2.8) & $(4.6)^{* *}$ & $(4.5)^{* *}$ & (7.4) \\
\hline \multirow[t]{2}{*}{0} & -6.1 & -7.0 & -4.8 & -19.8 & -15.3 & -1.0 \\
\hline & $(2.1)^{* *}$ & $(2.3)^{* *}$ & (3.0) & $(4.8)^{* *}$ & $(5.0)^{* *}$ & (6.4) \\
\hline \multirow[t]{2}{*}{1} & -11.6 & -14.7 & -11.7 & -30.7 & -22.9 & -3.3 \\
\hline & $(2.2)^{* *}$ & $(2.4)^{* *}$ & $(3.1)^{* *}$ & $(5.0)^{* *}$ & $(5.2)^{* *}$ & (5.5) \\
\hline \multirow[t]{2}{*}{2} & -12.7 & -16.4 & -12.8 & -29.4 & -21.9 & -8.0 \\
\hline & $(2.2)^{* *}$ & $(2.4)^{* *}$ & $(2.9)^{* *}$ & $(5.1)^{* *}$ & $(5.9)^{* *}$ & (5.7) \\
\hline \multirow[t]{2}{*}{3} & -12.6 & -16.6 & -11.6 & -30.7 & -24.2 & -6.9 \\
\hline & $(2.1)^{* *}$ & $(2.5)^{* *}$ & $(3.0)^{* *}$ & $(4.8)^{* *}$ & $(6.3)^{* *}$ & (5.9) \\
\hline \multirow[t]{2}{*}{4} & -11.6 & -16.4 & -9.4 & -32.7 & -27.0 & -7.7 \\
\hline & $(2.2)^{* *}$ & $(2.5)^{* *}$ & $(3.0)^{* *}$ & $(5.3)^{* *}$ & $(5.9)^{* * *}$ & (6.2) \\
\hline \multirow[t]{2}{*}{5} & -10.8 & -16.4 & -6.2 & -34.3 & -24.0 & -3.5 \\
\hline & $(2.3)^{* *}$ & $(2.5)^{* *}$ & $(3.0)^{*}$ & $(5.8)^{* *}$ & $(5.2)^{* *}$ & (6.2) \\
\hline \multirow[t]{2}{*}{6} & -11.4 & -15.4 & -4.6 & -33.2 & -22.1 & 2.0 \\
\hline & $(2.3)^{* *}$ & $(2.6)^{* *}$ & (3.0) & $(5.0)^{* *}$ & $(5.9)^{* *}$ & (6.0) \\
\hline \multirow[t]{2}{*}{7} & -10.6 & -14.9 & -2.7 & -39.5 & -22.9 & 6.6 \\
\hline & $(2.2)^{* *}$ & $(2.6)^{* *}$ & (3.0) & $(6.4)^{* *}$ & $(6.3)^{* *}$ & (6.1) \\
\hline Observations & 87780 & 74595 & 53445 & 10800 & 110040 & 48060 \\
\hline
\end{tabular}

Note: The sample comes from pooled SIPP data (panel years 1990, 1991, 1992, 1993, and 1996) merged to longitudinal earnings records. Age is based on one's age at period zero. "Low education" is defined as a high school diploma or less; "High education" is defined as some college or more. Standard errors, clustered by person, are in parentheses. See Appendix for further details. * and ${ }^{* *}$ signify statistical significance at the five and one percent levels. 
Table 3

Three-Year Divorce Hazard among Males by Education, Any Disability Onset Status, and Age

\begin{tabular}{|c|c|c|c|c|c|c|}
\hline & \multicolumn{3}{|c|}{ Low Education } & \multicolumn{3}{|c|}{ High Education } \\
\hline & $\begin{array}{c}\text { Nondisabled } \\
\mathrm{a}\end{array}$ & $\begin{array}{c}\text { Any Disability } \\
\text { b }\end{array}$ & $\begin{array}{c}\text { Difference } \\
\text { b-a }\end{array}$ & $\begin{array}{c}\text { Nondisabled } \\
\text { m }\end{array}$ & $\begin{array}{c}\text { Any Disability } \\
\mathrm{n}\end{array}$ & $\begin{array}{c}\text { Difference } \\
\text { m-n }\end{array}$ \\
\hline \multicolumn{7}{|l|}{ Age } \\
\hline \multirow[t]{3}{*}{$29-40$} & 7.0 & 8.8 & 1.8 & 5.4 & 10.6 & 5.2 \\
\hline & $(0.32)$ & (1.6) & (1.7) & $(0.24)$ & $(2.1)$ & $(2.1)$ \\
\hline & [6583] & [301] & & [9065] & [218] & \\
\hline \multirow[t]{3}{*}{$41-52$} & 3.6 & 6.2 & 2.5 & 3.8 & 7.9 & 4.1 \\
\hline & $(0.26)$ & (1.13) & $(1.2)$ & $(0.23)$ & (1.8) & (1.9) \\
\hline & [5251] & [456] & & [6869] & [216] & \\
\hline \multirow[t]{3}{*}{$53-64$} & 1.0 & 0.5 & -0.5 & 1.5 & 2.4 & 0.9 \\
\hline & $(0.16)$ & $(0.28)$ & $(0.32)$ & $(0.21)$ & $(0.97)$ & $(0.99)$ \\
\hline & [4030] & [649] & & [3381] & [251] & \\
\hline
\end{tabular}

Note: The sample is pooled SIPP data (1990, 1991, 1992, 1993, and 1996). The divorce hazard is calculated over a three-year period; for individuals who report a work-limiting disability, this period begins17 months prior to and ends 18 months after the month of the work limitation onset. Age is based on one's age at the beginning of the period. "Low education" is defined as a high school diploma or less; "High education" is defined as some college or more. Standard errors are in parentheses; sample sizes are in brackets. Sample weights were used. 


\section{Table 4}

Three-Year Divorce Hazard among Males by Education, Work-Preventing Disability Onset Status, and Age

\begin{tabular}{|c|c|c|c|c|c|c|}
\hline \multirow[b]{4}{*}{ Age } & \multicolumn{3}{|c|}{ Low Education } & \multicolumn{3}{|c|}{ High Education } \\
\hline & \multicolumn{3}{|c|}{ Preventing } & \multicolumn{3}{|c|}{ Preventing } \\
\hline & $\begin{array}{c}\text { Nondisabled } \\
\mathrm{a}\end{array}$ & $\begin{array}{c}\text { Disability } \\
\text { b }\end{array}$ & $\begin{array}{c}\text { Difference } \\
\text { b-a }\end{array}$ & $\begin{array}{c}\text { Nondisabled } \\
\mathrm{m}\end{array}$ & $\begin{array}{c}\text { Disability } \\
\mathrm{n}\end{array}$ & $\begin{array}{c}\text { Difference } \\
\text { m-n }\end{array}$ \\
\hline & & & & & & \\
\hline \multirow[t]{3}{*}{$29-40$} & 7.0 & 10.1 & 3.0 & 5.4 & 25.6 & 20.2 \\
\hline & $(0.32)$ & (2.8) & (2.9) & $(0.24)$ & (6.1) & (6.1) \\
\hline & [6583] & [113] & & [9065 ] & [52] & \\
\hline \multirow[t]{3}{*}{$41-52$} & 3.6 & 6.1 & 2.5 & 3.8 & 12.5 & 8.7 \\
\hline & $(0.26)$ & (1.6) & (1.6) & $(0.23)$ & (4.3) & (4.4) \\
\hline & [5251] & [219] & & [6869] & [59] & \\
\hline \multirow[t]{3}{*}{$53-64$} & 1.0 & 0.4 & -0.6 & 1.5 & 2.3 & 0.8 \\
\hline & $(0.16)$ & $(0.34)$ & $(0.37)$ & $(0.21)$ & (1.4) & (1.4) \\
\hline & [4030] & [375] & & [3381] & [115] & \\
\hline
\end{tabular}

Note: The sample is pooled SIPP data (1990, 1991, 1992, 1993, and 1996). The divorce hazard is calculated over a three-year period; for individuals who report a work-limiting disability, this period begins 17 months prior to and ends 18 months after the month of the work limitation onset. Age is based on one's age at the beginning of the period. "Low education" is defined as a high school diploma or less; "High education" is defined as some college or more. Standard errors are in parentheses; sample sizes are in brackets. Sample weights were used. 
Table 5

Probability Model Estimates of Divorce among Males

Linear Probability Model

\begin{tabular}{|c|c|c|c|c|c|c|c|}
\hline \multicolumn{2}{|c|}{ Any Disability } & \multicolumn{2}{|c|}{ Preventing Only } & \multicolumn{2}{|c|}{ Any Disability } & \multicolumn{2}{|c|}{ Preventing Only } \\
\hline 5.24 & 3.01 & 20.21 & 13.3 & 3.90 & 2.21 & 16.06 & 10.74 \\
\hline$(2.30)^{*}$ & (1.97) & $(7.02) * *$ & $(5.32)^{*}$ & $(1.74)^{*}$ & $(1.45)$ & $(5.95)^{* *}$ & $(4.75)^{*}$ \\
\hline-1.13 & 0.5 & -11.5 & -5.41 & 0.01 & 0.75 & -2.00 & -0.90 \\
\hline (3.16) & $(2.8)$ & (8.6) & (6.93) & $(1.60)$ & $(1.72)$ & $(1.42)$ & (1.56) \\
\hline-4.34 & -2.13 & -19.38 & -12.43 & -1.19 & -0.38 & -3.26 & -2.25 \\
\hline$(2.51)$ & (2.13) & $(7.15)^{* *}$ & $(5.45)^{*}$ & $(1.34)$ & $(1.41)$ & $(0.56)^{* *}$ & $(0.65)^{* *}$ \\
\hline-3.48 & -3.1 & -17.19 & -12.59 & -1.61 & -1.44 & -3.27 & -2.51 \\
\hline (3.01) & $(2.58)$ & $(7.75)^{*}$ & $(5.92)^{*}$ & $(0.94)$ & $(0.77)$ & $(0.52)^{* *}$ & $(0.40)^{* *}$ \\
\hline 1.87 & 2.23 & 10.95 & 8.02 & 1.18 & 1.61 & 4.31 & 5.04 \\
\hline (3.92) & $(3.47)$ & (9.38) & $(7.62)$ & $(2.58)$ & (2.69) & (6.05) & $(6.27)$ \\
\hline 2.1 & 1.65 & 15.79 & 11.12 & -1.28 & -1.51 & 2.84 & 0.76 \\
\hline (3.19) & $(2.72)$ & $(7.88)^{*}$ & $(6.05)$ & $(1.85)$ & $(1.21)$ & (5.81) & (3.96) \\
\hline No & Yes & No & Yes & No & Yes & No & Yes \\
\hline
\end{tabular}

Controls

Note: The sample is pooled SIPP data (1990, 1991, 1992, 1993, and 1996). The divorce hazard is calculated over a three-year period; for individuals who report a work-limiting disability, this period begins 17 months prior to and ends 18 months after the month of the work limitation onset. Age is based on one's age at the beginning of the period. "Low education" is defined as a high school diploma or less; "High education" is defined as some college or more. Probit estimates are reported as marginal effects. Standard errors are in parentheses; sample sizes are in brackets. Sample weights were used. * and ** signify statistical significance at the five and one percent levels. 
Table 6

Probability Model Estimates of Divorce among Females

\begin{tabular}{|c|c|c|c|c|c|c|c|c|}
\hline \multirow[b]{3}{*}{ Disabled } & \multicolumn{4}{|c|}{ Linear Probability Model } & \multicolumn{4}{|c|}{ Probit Model } \\
\hline & \multicolumn{2}{|c|}{ Limiting and Prevent } & \multicolumn{2}{|c|}{ Preventing Only } & \multicolumn{2}{|c|}{ Limiting and Prevent } & \multicolumn{2}{|c|}{ Preventing Only } \\
\hline & $\begin{array}{c}4.19 \\
(2.21)\end{array}$ & $\begin{array}{c}3.3 \\
(1.97)\end{array}$ & $\begin{array}{c}3.43 \\
(4.26)\end{array}$ & $\begin{array}{c}4.43 \\
(4.22)\end{array}$ & $\begin{array}{c}2.55 \\
(1.39)\end{array}$ & $\begin{array}{c}2.01 \\
(1.24)\end{array}$ & $\begin{array}{c}2.08 \\
(2.66)\end{array}$ & $\begin{array}{c}2.6 \\
(2.59)\end{array}$ \\
\hline *(Age 41-52) & $\begin{array}{l}-2.21 \\
(2.83)\end{array}$ & $\begin{array}{l}-1.02 \\
(2.61)\end{array}$ & $\begin{array}{c}-2.6 \\
(4.83)\end{array}$ & $\begin{array}{l}-3.02 \\
(4.81)\end{array}$ & $\begin{array}{l}-0.47 \\
(1.28)\end{array}$ & $\begin{array}{l}-0.08 \\
(1.25)\end{array}$ & $\begin{array}{l}-0.87 \\
(1.93)\end{array}$ & $\begin{array}{l}-0.75 \\
(1.64)\end{array}$ \\
\hline *(Age 53-64) & $\begin{array}{l}-3.19 \\
(2.58)\end{array}$ & $\begin{array}{l}-1.93 \\
(2.38)\end{array}$ & $\begin{array}{l}-3.66 \\
(4.3)\end{array}$ & $\begin{array}{l}-4.36 \\
(4.27)\end{array}$ & $\begin{array}{c}0.16 \\
(2.44)\end{array}$ & $\begin{array}{c}1.11 \\
(2.77)\end{array}$ & $\begin{array}{l}-1.82 \\
(1.55)\end{array}$ & $\begin{array}{c}-1.53 \\
(1.31)\end{array}$ \\
\hline Disabled and Low Education & $\begin{array}{c}0.23 \\
(2.95)\end{array}$ & $\begin{array}{l}-0.81 \\
(2.6)\end{array}$ & $\begin{array}{c}3.77 \\
(5.68)\end{array}$ & $\begin{array}{l}-1.54 \\
(5.37)\end{array}$ & $\begin{array}{c}0.11 \\
(1.22)\end{array}$ & $\begin{array}{l}-0.32 \\
(0.99)\end{array}$ & $\begin{array}{c}1.7 \\
(3.07)\end{array}$ & $\begin{array}{c}-0.58 \\
(1.63)\end{array}$ \\
\hline *(Age 41-52) & $\begin{array}{l}-1.46 \\
(3.54)\end{array}$ & $\begin{array}{c}-0.33 \\
(3.22)\end{array}$ & $\begin{array}{l}-3.92 \\
(6.23)\end{array}$ & $\begin{array}{c}1.18 \\
(5.93)\end{array}$ & $\begin{array}{l}-0.67 \\
(1.57)\end{array}$ & $\begin{array}{c}0.07 \\
(1.73)\end{array}$ & $\begin{array}{l}-1.11 \\
(2.15)\end{array}$ & $\begin{array}{c}0.77 \\
(3.43)\end{array}$ \\
\hline *(Age 53-64) & $\begin{array}{c}-0.77 \\
(3.28)\end{array}$ & $\begin{array}{c}-0.32 \\
(2.96)\end{array}$ & $\begin{array}{l}-3.18 \\
(5.75)\end{array}$ & $\begin{array}{c}1.74 \\
(5.44)\end{array}$ & $\begin{array}{c}-0.82 \\
(2.22)\end{array}$ & $\begin{array}{l}-1.08 \\
(1.64)\end{array}$ & $\begin{array}{l}0.54 \\
(4.3)\end{array}$ & $\begin{array}{c}2.17 \\
(5.47)\end{array}$ \\
\hline Controls & No & Yes & No & Yes & No & Yes & No & Yes \\
\hline
\end{tabular}

Note: The sample is pooled SIPP data (1990, 1991, 1992, 1993, and 1996). The divorce hazard is calculated over a three-year period; for individuals who report a work-limiting disability, this period begins 17 months prior to and ends 18 months after the month of the work limitation onset. Age is based on one's age at the beginning of the period. "Low education" is defined as a high school diploma or less; "High education" is defined as some college or more. Probit estimates are reported as marginal effects. Standard errors are in parentheses; sample sizes are in brackets. Sample weights were used. * and ** signify statistical significance at the five and one percent levels. 


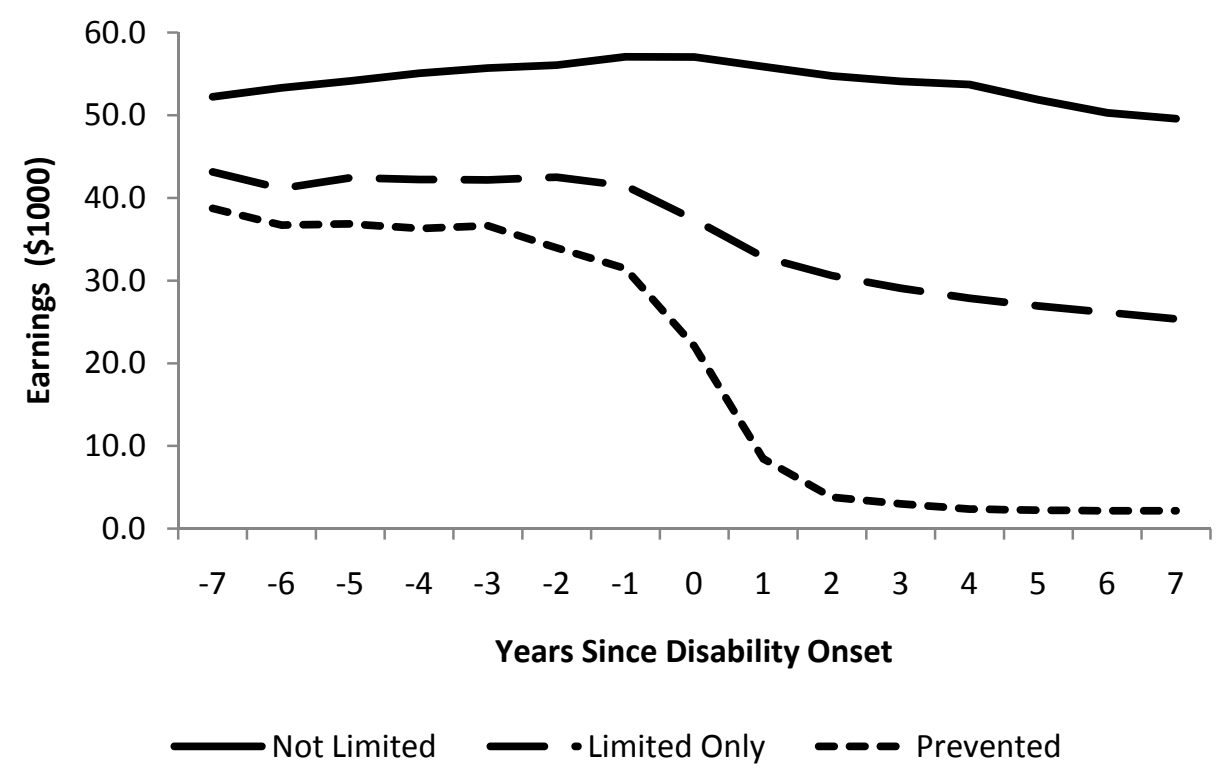

Figure 1: Average Annual Earnings by Disability Status among Males. 


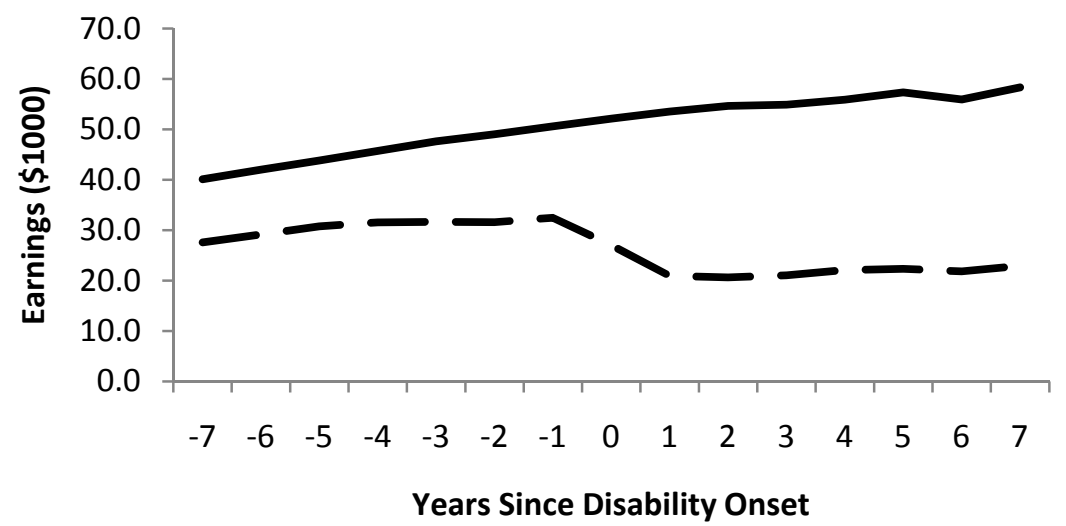

Not Limited $\longrightarrow$ - Limited

Panel A: Ages 29 to 40

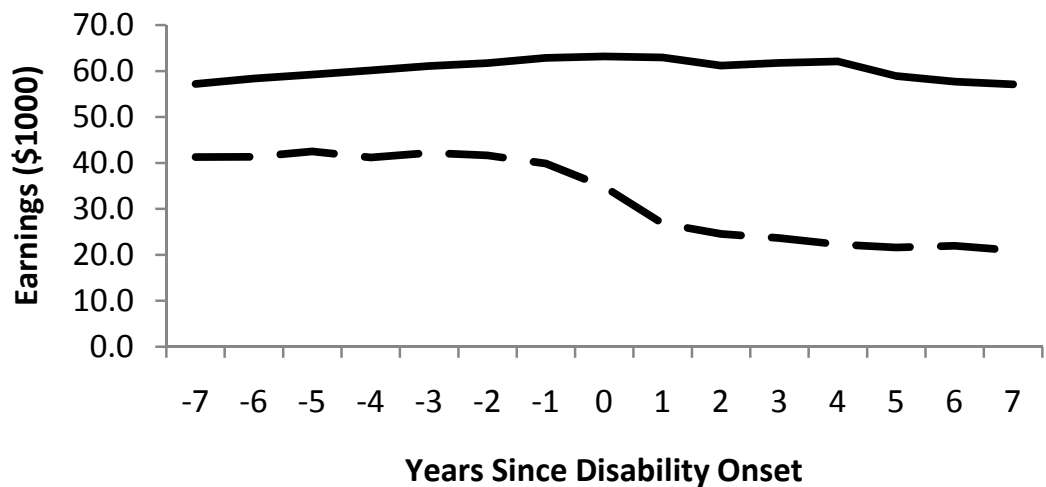

$\longrightarrow$ Not Limited $\quad$ - Limited

Panel B: Ages 41 to 52

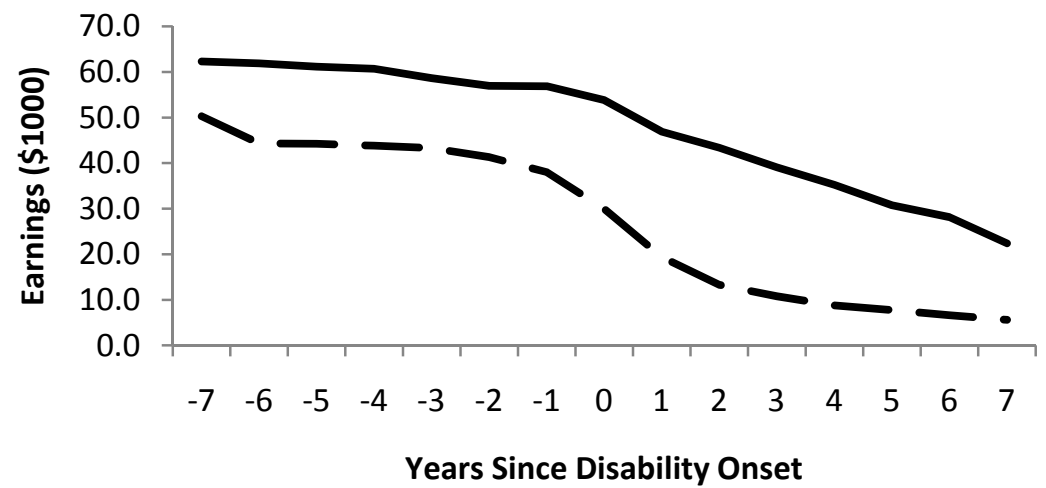

Not Limited $\quad \cdot$ Limited

Panel C: Ages 53 to 64

Figure 2: Average Annual Earnings by Disability Status among Males 


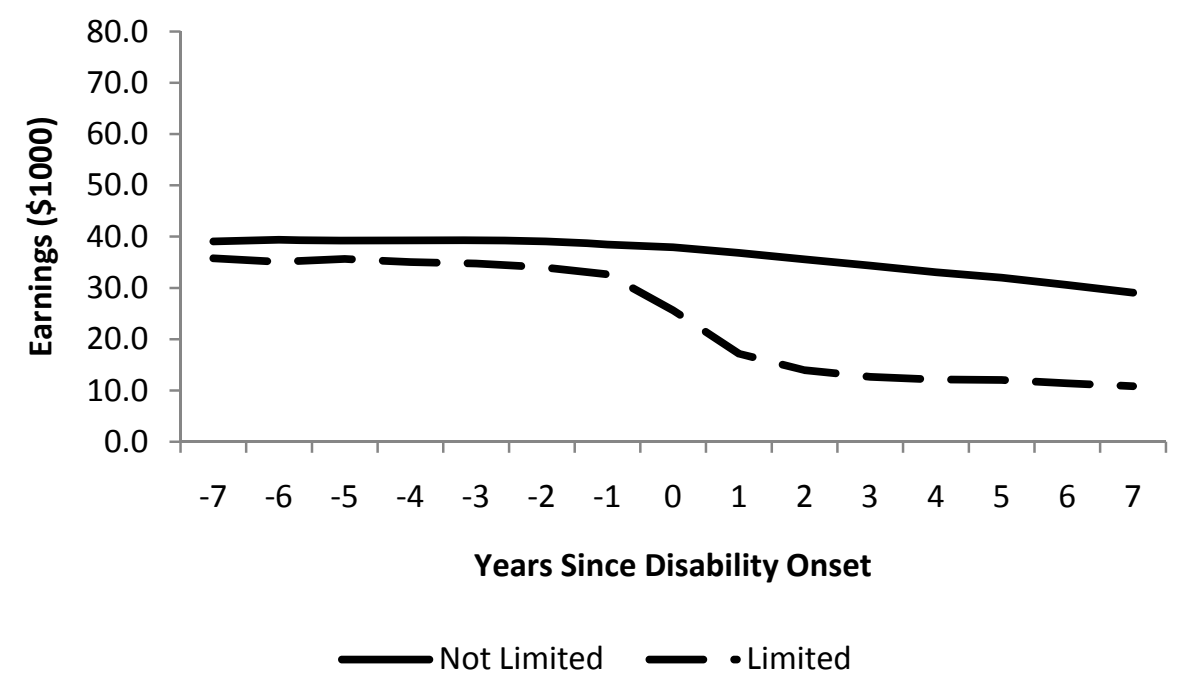

Panel A: Low Education



Figure 3: Average Annual Earnings by Disability Status among Males 


\section{RECENT WORKING PAPERS FROM THE}

\section{CENTER FOR RETIREMENT RESEARCH AT BOSTON COLLEGE}

Medicare Part D and the Financial Protection of the Elderly

Gary V. Engelhardt and Jonathan Gruber, October 2009

The Role of Information for Retirement Behavior: Evidence Based on the Stepwise Introduction of the Social Security Statement

Giovanni Mastrobuoni, October 2009

Social Security and the Joint Trends in Labor Supply and Benefits Receipt Among Older Men

Bo MacInnis, October 2009

The Wealth of Older Americans and the Sub-Prime Debacle Barry Bosworth and Rosanna Smart, October 2009

The Asset and Income Profile of Residents in Seniors Care Communities Norma B. Coe and Melissa Boyle, September 2009

Pension Buyouts: What Can We Learn From the UK Experience?

Ashby H.B. Monk, September 2009

What Drives Health Care Spending? Can We Know Whether Population Aging is a 'Red Herring'?

Henry J. Aaron, September 2009

Unusual Social Security Claiming Strategies: Costs and Distributional Effects Alicia H. Munnell, Steven A. Sass, Alex Golub-Sass, and Nadia Karamcheva, August 2009

Determinants and Consequences of Moving Decisions for Older Homeowners

Esteban Calvo, Kelly Haverstick, and Natalia A. Zhivan, August 2009

The Implications of Declining Retiree Health Insurance

Courtney Monk and Alicia H. Munnell, August 2009

Capital Income Taxes With Heterogeneous Discount Rates

Peter Diamond and Johannes Spinnewijn, June 2009

Are Age-62/63 Retired Worker Beneficiaries At Risk?

Eric R. Kingson and Maria T. Brown, June 2009

All working papers are available on the Center for Retirement Research website

(http://www.bc.edu/crr) and can be requested by e-mail (crr@bc.edu) or phone (617-552-1762). 